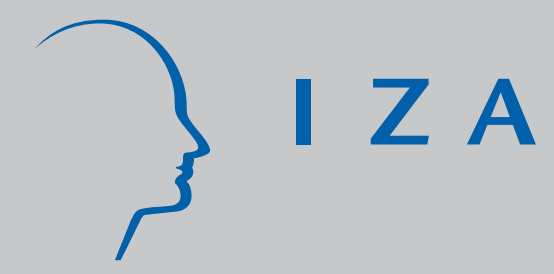

IZA DP No. 521

Employment Status, Endogenous Regional Mobility, and Spatial Dependencies in Labor Markets

René Fahr

Uwe Sunde

J une 2002 


\title{
Employment Status, Endogenous Regional Mobility, and Spatial Dependencies in Labor Markets
}

\author{
René Fahr \\ IZA Bonn and University of Bonn \\ Uwe Sunde \\ IZA Bonn and University of Bonn
}

Discussion Paper No. 521

June 2002

IZA

P.O. Box 7240

D-53072 Bonn

Germany

Tel.: +49-228-3894-0

Fax: +49-228-3894-210

Email: iza@iza.org

This Discussion Paper is issued within the framework of IZA's research area Mobility and Flexibility of Labor. Any opinions expressed here are those of the author(s) and not those of the institute. Research disseminated by IZA may include views on policy, but the institute itself takes no institutional policy positions.

The Institute for the Study of Labor (IZA) in Bonn is a local and virtual international research center and a place of communication between science, politics and business. IZA is an independent, nonprofit limited liability company (Gesellschaft mit beschränkter Haftung) supported by the Deutsche Post AG. The center is associated with the University of Bonn and offers a stimulating research environment through its research networks, research support, and visitors and doctoral programs. IZA engages in (i) original and internationally competitive research in all fields of labor economics, (ii) development of policy concepts, and (iii) dissemination of research results and concepts to the interested public. The current research program deals with (1) mobility and flexibility of labor, (2) internationalization of labor markets, (3) the welfare state and labor markets, (4) labor markets in transition countries, (5) the future of labor, (6) evaluation of labor market policies and projects and (7) general labor economics.

IZA Discussion Papers often represent preliminary work and are circulated to encourage discussion. Citation of such a paper should account for its provisional character. A revised version may be available on the IZA website (www.iza.org) or directly from the author. 


\title{
ABSTRACT \\ Employment Status, Endogenous Regional Mobility, and Spatial Dependencies in Labor Markets*
}

This paper investigates spatial correlation in the matching process of vacant jobs and job seekers. The importance of the interactions of regional labor markets in West Germany is highlighted in several dimensions. We test for spatial autocorrelation in regional hires, unemployment and vacancy levels, we examine the patterns of new matches in regions, identify clusters of regions of particularly intense interregional matching, and examine the effects of German re-unification. After setting-out a simple model of endogenous regional mobility and endogenous on-the-job search, we analyze the composition of new hires with respect to regional origin and previous employment status, the determinants of this composition, and the interaction of these characteristics. The results shed new light on the puzzle raised in the literature, which finds a large variation in unemployment rates, combined with little inter-regional migration. We find evidence in favor of labor market determined migration and against the 'internal migration puzzle' found for other European countries and partly for the United States.

JEL Classification: J61, J64, J21, R12

Keywords: internal migration, on-the-job search, job competition, composition of hires, unemployment

\author{
Uwe Sunde \\ IZA \\ PO Box 7240 \\ 53072 Bonn \\ Germany \\ Tel.: +492283894533 \\ Fax: +492283894210 \\ Email: sunde@iza.org
}

\footnotetext{
* We thank our colleagues at IZA for helpful comments and discussion. All errors are our own. Financial support from DFG is gratefully acknowledged.
} 


\section{Introduction}

The question whether local labor market conditions, in particular unemployment rates, affect regional mobility has been a concern for an extensive branch of literature (see Greenwood (1997) for a survey). In general, the empirical findings suggest that local unemployment influences internal migration decisions of unemployed individuals in the United States, see DaVanzo (1978). However, this relationship apparently fails to hold for European countries, see Pissarides and Wadsworth (1989) for the UK, Antolin and Bover (1997) for Spain, and Faini, Galli, Gennari, and Rossi (1997) for Italy. Generally, migration decisions of employed seem not affected by labor market conditions, see Greenwood (1997) for an extensive overview over empirical findings.

The purpose of this paper is twofold. In the first, rather explorative, part we investigate spatial dependencies in the (West-)German labor market, in particular in the context of the search and matching process between unemployed job seekers and vacant jobs. We deal with questions such as: Do geographic environment and spatial issues matter for the matching process? In particular, does the general job situation of neighboring regions matter for the job creation in a given region, even if regions are broadly defined as travel-to-work areas? Are there differences in the spatial structures of all matches, matches from unemployment and job-to-job transitions, and do regions compete against each other for matches of these categories? In other words, is there measurable regional job competition? Did German re-unification have a measurable impact on internal migration behavior in West Germany? We address these issues by providing evidence for spatial autocorrelation in labor market variables. We examine spatially augmented empirical matching functions, and we study the regional structure of labor market flows. Finally, we isolate regions of particularly intense inter-regional dependencies of labor markets, so-called hot spots and clusters, and estimate the matching efficiencies of different regional labor markets. Our findings extend previous literature on spatial matching, including Gorter and Van Ours (1994), Burda and Profit (1996) and Burgess and Profit (2001) in several aspects. We present the first thorough analysis of this kind for Germany, and extend the spatial frameworks used before by an extensive specification analysis. Moreover, unlike any of the previous contributions, our data allow to decompose labor market flows simultaneously along the spatial dimension as well as previous employment status, and therefore provide the possibility to perform much more detailed and precise investigations. The results serve as a motivation for a more structural approach to explain the data patterns.

The second part deals directly with the questions raised in the literature: 
Is regional migration determined by the state of labor markets? Do employed workers differ systematically in their regional search and migration behavior from unemployed individuals? And, finally, is there also a geographic labor market puzzle in Germany, in the sense that there is little regional mobility despite a large variation in job market conditions and unemployment rates. Economic theory would suggest that regional migration would be triggered by higher job finding probabilities elsewhere, and hence serve to equilibrate inter-regional differences in unemployment rates and job market conditions.

In order to shed new light on these questions, we present a simple model with endogenous regional mobility, and endogenous on-the-job search behavior. The resulting competition for jobs along two dimensions determines the composition of new hires with respect to the characteristics of the newly hired. We test the implications of the theoretical model empirically with detailed regional panel data for Western Germany, which also allow to investigate whether regional migration behavior was affected by German reunification.

The paper proceeds as follows. Section 2 describes the data used throughout the analysis. In section 3 we investigate spatial dependencies in the labor market conditions and the job creation process across regional labor markets in West Germany. After providing evidence that conventional matching studies neglecting the spatial dimension of job creation are misspecified, section 4 presents results obtained using spatially augmented empirical matching functions. Moreover, we investigate the composition of new hires and its determinants, as well as the effects of German re-unification. In section 5, we develop a simple model of mobility and on-the-job search, and test its implications for their empirical validity. The findings confirm endogenous behavior in both dimensions, and imply considerable mobility and on-the-job search. Section 6 concludes.

\section{Data issues}

The data used for the analysis below are yearly data on unemployment, vacancies and hirings for the years 1980 until 1997 for Western Germany. The data are from official labor statistics and disaggregated at the regional level.

The hirings are measured on the individual level and stem from an anonymized representative $1 \%$ sample of German social security records provided by the German Federal Institute for Employment Research (IAB). The database is supplemented by data on unemployment benefits recipients and by establishment information (see Bender, Haas, and Klose (2000) for details). The 
data allow to identify hirings from one year to another for each region by source of hiring. Specifically, hirings from out of the labor force, from unemployment, and from employment can be distinguished. In addition we can identify whether a hiring is from the same region, a neighbouring region or from a non-neighbouring region. The region is thereby defined by the location of the notifying (plant of) current employer.

The IAB regional file provides regional information on the district level. To ensure anonymity these districts are aggregated in a way that they include at least 100,000 inhabitants. As we want to analyze relevant labor markets we use information on travel to work areas provided by the Federal Office for Building and Regional Planning to aggregate these districts to broader regions. In only a few cases it was necessary to aggregate these labor market districts even further to match the employment office districts, the level of regional aggregation at which the information on stocks of unemployed and vacancies is provided. A list with the labor market regions used in the empirical analysis, as well as a map indicating their location, are contained in the Appendix. The hirings are calculated for the reference date end of September of each year while the stocks are reported as yearly averages.

\section{Spatial Dependencies in the Labor Market}

This section attempts to shed some light on spatial dependencies in the labor market. In particular, we investigate whether new jobs, i. e. newly created employer-employee matches are spatially autocorrelated, and whether the labor market conditions (levels of new matches, vacancies and unemployment) in neighboring regions matter for the job creation process within a region. The section proceeds as follows. First, we employ tests for global spatial autocorrelation on the data for new matches. We then investigate this issue in some more detail and ask whether there is evidence for local spatial autocorrelation and clusters of regions affecting each other with respect to labor market outcomes.

The absence of evidence for spatial autocorrelation would indicate that considering geographic aspects is not crucial for modelling the labor market. However, we find indications for spatial effects. Therefore, we next estimate conventional $U / V$-matching functions and test for misspecification. In particular, we test the conventional model against alternatives like spatial autoregression in the dependent variable and spatially autoregressive error terms. Later, we also provide results from regressing spatial specifications of the matching function, including specifications instrumenting the (spatially) lagged dependent variable using (spatially) lagged explanatory variables. 


\subsection{Global and Local Spatial Autocorrelation}

In order to reveal the spatial pattern of search and matching behavior on the labor market, we first test whether the variables of primary interest in the context of empirical labor market matching exhibit spatial autocorrelation. Spatial autocorrelation means that the spatial distribution of new successful matches during a certain defined period of time (in our case a year) exhibits a systematic pattern. In other words, if new matches are positively spatially autocorrelated, a high job creation activity in a certain region is associated with high job creation in nearby regions. Since the data we use consist of cells of 117 West-German labor market regions (comparable to travel-to-work areas, see data section and the appendix for a description and a map of the regions) we define contiguity between two regions as the regions sharing a common border. The corresponding spatial weights matrix $W$ is therefore a symmetric $117 \times 117$ matrix with entries 0 and 1 , where 1 indicates contiguity. ${ }^{1}$ In order to test the null hypothesis of no spatial autocorrelation, we employ Moran's I-test for global spatial autocorrelation, see Anselin and Bera (1999) for details. Where appropriate, we also report results for alternative measures of global autocorrelation like Geary's $c$ and Getis and Ord's $G .^{2}$ Moran's $I$ is defined as:

$$
I=\frac{\sum_{i=1}^{N} \sum_{j=1}^{N} w_{i j}\left(Y_{i}-\bar{Y}\right)\left(Y_{j}-\bar{Y}\right)}{\left(\sum_{i=1}^{N} \sum_{j=1}^{N} w_{i j}\right) \sum_{i=1}^{N} \frac{\left(Y_{i}-\bar{Y}\right)^{2}}{N}},
$$

where $Y$ is the variable of interest, $\bar{Y}$ denotes the (cross-sectional) mean of $Y$, and $w_{i j}$ is the element of the spatial weights matrix $W$ corresponding to the location pair $(i, j)$. Under the null hypothesis of no spatial autocorrelation, the expected value of $I$ is $E(I)=\frac{-1}{N-1}$. If $I$ is larger than this, then $Y$ has a distribution characterized by positive spatial autocorrelation, in the sense that high values of $Y$ are associated with high realizations of $Y$ in spatially contiguous regions. The opposite holds for values of $I$ smaller than this value, indicating negative spatial autocorrelation. Inference is based on $z_{I}=\frac{I-E(I)}{s d(I)}$, where $s d(I)$ is the standard deviation of $I$.

Since also the structure of the explanatory variables matters for the empirical matching context, we apply the testing procedures on new matches, the dependent variable, and on the stocks of unemployed and vacancies. Unfortunately, these three tests only utilize the cross-sectional dimension of the data. Therefore, we replicate the tests for each time period within the observation window 1980-1997. For reasons of space we only report the general

\footnotetext{
${ }^{1}$ The entries on the main diagonal of $W$ are zeros, since a region cannot be contiguous to itself.

${ }^{2}$ The respective test statistics are discussed in Appendix A.
} 
findings. Detailed results are available from the authors upon request. The results can be summarized as follows. There is strong evidence for positive spatial autocorrelation of the explanatory variables, unemployment and vacancies, as measured by Moran's I and Geary's c. However, the null cannot be rejected for the dependent variable, hires. The analysis of Getis and Ord's $G$, leads to somewhat different conclusions. ${ }^{3}$ According to this measure, new matches are spatially autocorrelated and characterized by strong high-valued global clustering. On the other hand, evidence for clustering in the explanatory variables, particularly regional unemployment, is weak. These results are interesting in the light of previous results in the literature. Burgess and Profit (2001) use data for Great Britain and test their two concepts of dependent variables, outflows from unemployment and filled vacancies, for spatial autocorrelation using Moran's I-test. They find strong evidence for spatial spillovers in matching, while our findings suggest that there is only very weak if any spatial autocorrelation in the dependent variables.

Next, we test for local spatial autocorrelation in the data. It turns out that spatial patterns exhibit substantial heterogeneity across regions. Moreover, this heterogeneity is fairly stable over time, in the sense that regions with strong evidence for spatial autocorrelation at the beginning of the observation period (early 1980s) are also the regions for which the null is rejected strongly at the end of the observation period (mid/late 1990s). Table 1 contains the ten regions with the highest test scores for positive and negative spatial autocorrelation, respectively, as measured by Moran's $I$ on average over the years 1980 to 1997. Obviously, the Ruhr area around the cities Düsseldorf, Essen and Gelsenkirchen represents a huge common labor market, characterized by strong positive spatial autocorrelation. On the other hand, agglomeration areas surrounded by less densely populated, rural regions, like Hamburg, Frankfurt, Stuttgart and München constitute hot spots that attract many workers from surrounding areas during booms and set free many workers to surrounding areas during recessions.

\subsection{Spatial Misspecification of Conventional Matching Functions}

In order to find out more about spatial dependencies in the matching process, we regress conventional matching functions of the Cobb-Douglas specification

$$
\ln m_{i t}=A+\alpha \ln U_{i t}+\beta \ln V_{i t}+\varepsilon_{i t},
$$

\footnotetext{
${ }^{3}$ Compare Appendix A for a description and interpretation of Geary's $c$ and Getis and Ord's $G$.
} 
TABLE 1: RESUlTS FOR SPATIAL AUTOCORRELATION TESTS: HOT SPOTS AND CLUSTERS

\begin{tabular}{|c|c|c|c|}
\hline \multicolumn{2}{|c|}{$\begin{array}{c}\text { significant positive autocorrelation in hirings } \\
\text { CLUSTERS }\end{array}$} & \multicolumn{2}{|c|}{$\begin{array}{l}\text { significant negative autocorrelation in hirings } \\
\text { Hot SPOTS }\end{array}$} \\
\hline region number & region & region number & region \\
\hline 5 & Lübeck & 2 & Hamburg \\
\hline 16 & Leer & 3 & Heide \\
\hline 33 & Düsseldorf & 7 & Bremen \\
\hline 34 & Duisburg & 13 & Hannover \\
\hline 35 & Essen & 17 & Lüneburg \\
\hline 36 & Gelsenkirchen & 32 & Düren \\
\hline 39 & Köln & 51 & Frankfurt \\
\hline 42 & Mönchengladbach & 89 & Stuttgart \\
\hline 43 & Münster & 99 & Nürnberg \\
\hline 56 & Korbach & 112 & München \\
\hline
\end{tabular}

where $m_{i t}$ denotes the new matches created in region $i$ within a period of time, i. e. between $t$ and $t+1, U_{i t}$ is the number of unemployed job seekers in region $i$ at the observation period $t$, and $V_{i t}$ is the number of vacancies in $i$ at $t$, while $\alpha$ and $\beta$ are parameters. $\varepsilon$ denotes a vector of normally distributed, homoskedastic and uncorrelated errors. In the presence of spatial dependencies among observations, this model might be misspecified. Therefore, we test this model against two alternative specifications taking spatial dependencies explicitly into account. The first of these is the spatial error model. Essentially, a model identical to (2) is estimated, but imposing a different error structure:

$$
\varepsilon_{i t}=\lambda W \varepsilon_{i t}+\mu_{i t},
$$

with $W$ representing the spatial weights matrix mentioned above, $\lambda$ denoting the spatial autoregressive parameter, and $\mu$ denoting a vector of homoskedastic and uncorrelated errors. The second spatial model we consider is the following mixed regressive spatial autoregressive model, the spatial lag model:

$$
\ln m_{i t}=A+\alpha \ln U_{i t}+\beta \ln V_{i t}+\rho W m_{i t}+\varepsilon_{i t},
$$

where $\rho$ denotes the spatial autoregression parameter, and $W m_{i t}$ denotes the spatially lagged dependent variable (the weighted sum of contemporary matches in neighboring regions). Since the tests make no use of the time dimension but only of the cross-sectional (regional) variation of the data, we estimate and test the three models for each year between 1980 and 1997.

The results of these tests are displayed in Table 2 and reveal that the conventional specification of the matching function (2) can be rejected in favor of one or both alternative specifications for every year. For the years 1980, 1981, and 1989-1993, the conventional model is rejected in favor of the spatial lag model (4), that is the null that $\rho$ equals zero cannot be rejected 
TABLE 2: SPECIFICATION ANALYSIS: SPATIAL ERROR AND SPATIAL

LAG MODELS

\begin{tabular}{|c|c|c|c|c|}
\hline $\begin{array}{l}\text { Most preferred } \\
\text { specification: }\end{array}$ & $\begin{array}{c}\text { no spatial } \\
\text { effects } \\
\text { (4) }\end{array}$ & $\begin{array}{c}\text { spatial error } \\
\text { (5) }\end{array}$ & $\begin{array}{c}\text { spatial lag } \\
(6)\end{array}$ & $\begin{array}{c}\text { spatial error } \\
\text { and lag } \\
(5) \&(6)\end{array}$ \\
\hline 1980 & & & $\mathrm{X}$ & \\
\hline 1981 & & & $\mathrm{X}$ & \\
\hline 1982 & & & & $\mathrm{X}$ \\
\hline 1983 & & & & $\mathrm{X}$ \\
\hline 1984 & & $\mathrm{X}$ & & \\
\hline 1985 & & $\mathrm{X}$ & & \\
\hline 1986 & & $\mathrm{X}$ & & \\
\hline 1987 & & & & $\mathrm{X}$ \\
\hline 1988 & & & & $\mathrm{X}$ \\
\hline 1989 & & & $\mathrm{X}$ & \\
\hline 1990 & & & $\mathrm{X}$ & \\
\hline 1991 & & & $\mathrm{X}$ & \\
\hline 1992 & & & $\mathrm{X}$ & \\
\hline 1993 & & & $\mathrm{X}$ & \\
\hline 1994 & & & & $\mathrm{X}$ \\
\hline 1995 & & & & $\mathrm{X}$ \\
\hline 1996 & & & & $\mathrm{X}$ \\
\hline 1997 & & & & $\mathrm{X}$ \\
\hline
\end{tabular}

for these years, while the hypothesis that $\lambda$ equals zero can be rejected at conventional levels. For the years 1984-1986, the opposite is true. During all the remaining years, both null hypotheses can be rejected, suggesting that both types of spatial dependencies play a role in the matching process. This casts doubts on the validity of results obtained from matching studies using regional data that neglect spatial dependencies in the variables, like Gorter and Van Ours (1994).

As a next step, we search for the most preferred specification of the matching process by estimating spatial error and spatial lag models by maximum likelihood separately for each year. Using the estimation results we test whether the hypotheses that $\lambda=0$ in case of the spatial error model and $\rho=0$ in case of the spatial lag model can be rejected. Generally, with the exception of four (out of 18) years, we can reject neither hypothesis at the 5 percent level. However, $\rho=0$ can be rejected at more generous significance levels (around, say, 10 to 12 percent) in most years, in favor of the spatial lag model. On the other hand, $\lambda=0$ can be rejected only in three years, 1995-1997, and in the latter two significantly (at the 5 percent level) in favor of the spatial error model. The conclusion we draw from this is that there is evidence that spatial determinants play some role and therefore have to be contained in the correct specification of the matching function. The results point rather towards a spatial lag specification rather than a spatial error 
specification.

\section{Spatial Structure of Job Creation}

This section examines the matching and job creation process in some more detail with respect to spatial issues. The primary contribution of this section lies in the analysis of the composition of employment flows. In particular, we are able to decompose flows into employment in terms of regional origin and destination as well as employment status. The different flow measures used are all matches of individuals previously employed in the same region, in a neighboring region and in regions located further away (nonneighboring). Moreover we can decompose these flows further into matches of previously unemployed and previously employed individuals. ${ }^{4}$ It is obvious that the availability of such detailed data allows to address several interesting questions, like whether and how job creation is affected by locational circumstances, and whether unemployed or employed are more likely to move region for a new job.

The first part of this section is devoted to checking the robustness of the conventional matching function specification as presented in the previous section with respect to the choice of the dependent variable, that is the concept of matches used. Then, we look closer into the migration behavior of workers by investigating the spatial decomposition of matches and its dependence on the spatial structure of explanatory variables. These results provide the motivation for a structural model to be developed in the following section, which is used to shed more light on the regional mobility-unemployment puzzle in West Germany. As a third issue, we examine whether the German re-unification, which occurs after about half of the observation periods covered by our data, had an impact on regional migration behavior and the spatial composition of new matches.

\subsection{Spatially Augmented Matching Functions}

After the evidence for the hypothesis that spatial issues matter presented before, the first question one has in mind is whether the results obtained by conventional matching functions neglecting the spatial dimension can still come up with unbiased estimates. To answer this question, we estimate matching functions of specification (2) for different concepts of flows. In

\footnotetext{
${ }^{4}$ For workers who were unemployed before the current job we have information about the region of their last job.
} 
TABLE 3: COMPOSITION OF HIRES WITH RESPECT TO REGIONAL ORIGIN AND EMPLOYMENT STATUS

\begin{tabular}{|c|c|c|c|c|c|}
\hline & & \multicolumn{4}{|c|}{ Shares of total matchings $\boldsymbol{m}$} \\
\hline & & $\begin{array}{l}\text { from same } \\
\text { region }\end{array}$ & $\begin{array}{l}\text { from } \\
\text { neighbor } \\
\text { region }\end{array}$ & $\begin{array}{l}\text { from other } \\
\text { regions }\end{array}$ & $\begin{array}{l}\text { from all } \\
\text { regions }\end{array}$ \\
\hline & & $m_{h}$ & $m_{n}$ & $\boldsymbol{m}_{f}$ & $m$ \\
\hline \multicolumn{6}{|l|}{ Hirings: } \\
\hline from employment: & $m_{e}$ & 0.218 & 0.058 & 0.043 & 0.319 \\
\hline from unemployment: & $m_{u}$ & 0.200 & 0.028 & 0.032 & 0.260 \\
\hline $\begin{array}{l}\text { from employment and } \\
\text { unemployment }\end{array}$ & $m$ & 0.418 & 0.086 & 0.496 & $\begin{array}{c}(0.579) * \\
1.000\end{array}$ \\
\hline
\end{tabular}

Note: All data are aggregated over all 117 regions and averages over the period 1980-1997. Table entries are shares of the respective group characterized by regional status prior to current match and employment status prior to current match, with respect to total shares (that is they add up to $100 \%$ horizontally).

* The data cannot identify regional origin of new matches from out of the labor force. Therefore, only $57.9 \%$ of the new matches can be decomposed regionally. New hires from out of the labor force, making up for 42.1 $\%$ of all hires, are contained in all hires $\boldsymbol{m}$, but we refrain from analyzing them separately. Hires with missing region identifier are coded as "from other regions" $\boldsymbol{m}_{\boldsymbol{f}}$, hires with missing employment status identifier are coded as from out of the labor force.

particular, we compare the results obtained by taking all flows $m$ as dependent variable with estimations for taking only individuals stemming from within the region $\left(m_{h}\right)$, new matches of individuals who were previously employed in neighboring regions $\left(m_{n}\right)$, or in other non-neighboring regions $\left(m_{f}\right)$. Alternatively, we can decompose flows by the job status of the respective new employed: individuals who were unemployed before successfully matching $\left(m_{u}\right)$, and previously employed job switchers $\left(m_{e}\right)$. Moreover, we have results for the same concepts, further decomposed as interactions, that is flows from unemployment decomposed by regional origin $\left(m_{u h}, m_{u n}, m_{u f}\right)$ and formerly employed job switchers decomposed by where they come from $\left(m_{e h}, m_{e n}, m_{e f}\right)$. Table 3 contains the sample averages of these different concepts of matches over all years and regions in order to give some information about the quantitative relevance of the different measures.

As a consequence of the results of the previous section, we estimate conventional matching functions augmented by spatially autoregressive components, as suggested by results on the spatial lag model specification. These estimations are conducted first separately for each year, utilizing only the cross-sectional variation of the data. Then, we also estimate matching functions using the entire panel structure of the data.

For brevity, we only report the main results for the pooled sample in Table $4 .^{5}$ As is standard in empirical studies of the matching function (see

\footnotetext{
${ }^{5}$ Detailed estimation results are available from the authors upon request.
} 
e.g. Petrongolo and Pissarides (2001)), we consistently find for yearly as well as pooled specifications that the stocks of unemployed and vacancies exhibit highly significant postitive effects on the number of matches with coefficients of between 0.35 and 0.55 for the majority of years under study. For the pooled specifications, the coefficients are consistently between 0.43 and 0.5.

More novel is that consistently for all yearly and pooled specifications we a find significant negative coefficient for the spatially lagged dependent variable if all hirings are used as dependent variable. In order to account for potential simultaneity bias, and for robustness, we then instrument the lagged dependent variable with spatially lagged observations of the explanatory variables. While the results for the local explanatory variables are virtually unaffected by this, the coefficient for lagged unemployment turns out to be significantly negative throughout all specifications, while the sign of the coefficient for lagged vacancies depends on the concept of the dependent variable used: the effect is significantly positive for all hires and hires from employment, significantly negative for unemployment outflows into employment. Burda and Profit (1996) also use regions sharing a common border as definition for spatial contiguity when estimating spatially augmented matching functions. They obtain, depending on the selection criterion for the dependent variable $^{6}$, somewhat different results with the effect of spatially lagged vacancies significantly positive in the baseline specification, significantly negative for non-border regions only. The effect of spatially lagged unemployment is either insignificant or negative.

The negative effect of matches in neighboring regions on the number of successful matches in a given region hints at competition for matches between regions. It seems that regions seem to fare better if their neighboring regions experience low new job creation rates. This is not quite what one would expect. In particular, this finding means that there is negative spatial autocorrelation among regions with respect to matches. However, the picture becomes a bit more differentiated once one instruments spatially lagged matches using spatially lagged unemployment and vacancy levels. The negative effect of unemployment in neighboring regions seems to catch a cyclical effect: the higher the unemployment rates in other regions, the worse the economic situation, resulting in fewer matches. This argumentation seems validated by the fact that unemployment rates are spatially autocorrelated, as was reported before. Moreover, the finding hints at congestion effects, since, if a certain number of vacancies is to be filled, more non-resident unemployed job applicants crowd-out local applicants thereby decreasing the

\footnotetext{
${ }^{6}$ That is, whether district dummies or dummies for macro regions or only non-border regions are included.
} 
Table 4: Empirical Matching FunCtions With SPATIAl DePEndence

\begin{tabular}{|c|c|c|c|c|c|c|}
\hline \multirow[b]{2}{*}{$y=\ln ($} & \multirow[b]{2}{*}{$m_{\text {all }}$} & \multicolumn{5}{|c|}{ Dependent Variables: } \\
\hline & & $m_{\text {all }}$ & $m_{u}$ & $m_{u}$ & $m_{e}$ & $\left.m_{e}\right)$ \\
\hline \multirow[t]{2}{*}{$\ln (U)$} & 0.451 & 0.553 & 0.572 & 0.512 & 0.385 & 0.594 \\
\hline & $(0.008)$ & $(0.023)$ & $(0.013)$ & $(0.026)$ & $(0.010)$ & $(0.026)$ \\
\hline \multirow[t]{2}{*}{$\ln (V)$} & 0.467 & 0.387 & 0.138 & 0.238 & 0.660 & 0.471 \\
\hline & $(0.009)$ & $(0.022)$ & $(0.013)$ & $(0.025)$ & $(0.011)$ & $(0.025)$ \\
\hline \multirow[t]{2}{*}{$\ln \left(W^{*} y\right)$} & -0.082 & & 0.056 & & 0.049 & \\
\hline & $(0.016)$ & & $(0.023)$ & & $(0.017)$ & \\
\hline \multirow[t]{2}{*}{$\ln (W U)$} & & -0.200 & & -0.048 & & -0.293 \\
\hline & & $(0.026)$ & & $(0.030)$ & & $(0.029)$ \\
\hline \multirow[t]{2}{*}{$\ln (W V)$} & & 0.014 & & -0.267 & & 0.215 \\
\hline & & $(0.024)$ & & $(0.028)$ & & $(0.028)$ \\
\hline \multirow[t]{2}{*}{ Linear time trend } & -0.039 & -0.032 & -0.026 & -0.012 & -0.037 & -0.035 \\
\hline & $(0.001)$ & $(0.001)$ & $(0.002)$ & $(0.001)$ & $(0.002)$ & $(0.002)$ \\
\hline \multirow[t]{2}{*}{ Constant } & 6.805 & 6.736 & 4.101 & 5.584 & 3.403 & 4.271 \\
\hline & $(0.197)$ & $(0.132)$ & $(0.235)$ & $(0.175)$ & $(0.197)$ & $(0.163)$ \\
\hline $\mathrm{R}^{2}$ & 0.816 & 0.827 & 0.617 & 0.654 & 0.805 & 0.817 \\
\hline Observations & 2106 & 2106 & 2106 & 2106 & 2106 & 2106 \\
\hline
\end{tabular}

efficiency of the matching process. On the other hand, the positive effect of labor demand conditions in neighboring regions, as measured by vacancy rates, seems to express cyclical contingencies between regions: If firms are willing to create more jobs and thus post more vacancies, this is positively correlated to the number of matches also in neighboring regions. This finding is corroborated by the positive spatial autocorrelation found for vacancies in the preceding section.

The results for the matching functions (including a constant and a linear time trend) exhibit highly significant, positive coefficients for both stocks, unemployed and vacancies for all concepts of flow data used as dependent variable. The time trend is significantly negative in all panel specifications. Overall, the significant effects of spatially lagged variables suggest that estimation results obtained with conventional matching functions neglecting spatial dependencies are biased.

Unlike previous studies of spatial matching functions, like Burda and Profit (1996) and Burgess and Profit (2001), we are able to distinguish labor market flows along several dimensions. When decomposing flows by source of origin, it turns out that while the elasticity of the respective concept of matches with respect to unemployment, $\hat{\alpha}$, is roughly the same as the elasticity with respect to vacancies, $\hat{\beta}$, or slightly smaller, $\hat{\alpha}$ is larger than $\hat{\beta}$ if flows out of unemployment into employment are considered. On the other hand, 
$\hat{\alpha}$ is smaller than $\hat{\beta}$ if job-to-job changes are regressed. These differences in the results can be expected as a result of misspecification stemming from omitting relevant unobservable explanatory variables in the estimation. A discussion of the underlying mechanisms leading to these results is beyond the scope of this paper. ${ }^{7}$ However, it is worth noting that spatially lagged unemployment has a consistently negative effect on matches regardless of the flow concept used as dependent variable. On the other hand, spatially lagged vacancies affect all hires, and hires from employment positively, but hires from unemployment significantly negatively. This can be interpreted as evidence that higher job creation activity elsewhere leads more unemployed to search elsewhere for jobs, and thus causes more regional emigration, indicating negative spatial autocorrelation in the reverse direction as discussed above.

The data allow us to investigate these issues further by checking whether this pattern remains once one considers regional heterogeneity among the new matches. Indeed, the differences are qualitatively the same, and quantitatively even slightly stronger when only matches of individuals who stayed within the same region $\left(m_{h}\right)$ are considered. ${ }^{8}$ The same is true for matches of individuals immigrating from neighboring regions. In contrast, results of coefficient estimates for flows from different labor market status do not differ for individuals immigrating from non-neighboring regions: $\hat{\alpha}$ is always slightly smaller than $\hat{\beta}$. These findings suggest that for intra-regional migration or migration between contiguous regions, labor market status has crucial effects on demand and supply elasticities, and therefore in some sense segments the labor market. On the other hand, status matters a lot less for far-distance migrants. These results are also broadly robust to estimations which only use cross-sectional variation (year-by-year).

\subsection{Hot Spots, Local Clusters and Matching Efficiency}

Using tests for local spatial autocorrelation, we have shown above that there is a group of regions all of which exhibit significant positive spatial autocorrelation in their hiring process, so called clusters. Likewise, there are hot spots whose job creation is significantly negatively autocorrelated. In order to in-

\footnotetext{
${ }^{7}$ See Sunde (2002) for a formal treatment of the bias resulting from an omission of unobservable endogenous search on both sides of the labor market. Another interpretation of the data indicates the relevance of an adverse selection mechanism, see Kugler and Saint-Paul (2001).

${ }^{8}$ Regionally decomposed employment flows will be investigated in more detail in section 4.3. Results for regional decomposition of flows are presented in Table 6, albeit for a somewhat different specification.
} 
Table 5: Empirical Spatially Augmented Matching FunCtions for Clusters AND HOT SPOTS

\begin{tabular}{|c|c|c|c|c|c|c|}
\hline \multirow{3}{*}{$\begin{array}{l}\text { Dependent Variable: } \\
\qquad y=\ln (\end{array}$} & \multicolumn{6}{|c|}{ Sample of Regions: } \\
\hline & \multicolumn{2}{|c|}{ All regions } & \multicolumn{2}{|c|}{$\begin{array}{c}\text { Clusters } \\
\text { (positive autocorr.) }\end{array}$} & \multicolumn{2}{|c|}{$\begin{array}{c}\text { Hot Spots } \\
\text { (negative autocorr.) }\end{array}$} \\
\hline & $\boldsymbol{m}_{\text {all }}$ & $\boldsymbol{m}_{\text {all }}$ & $\boldsymbol{m}_{\text {all }}$ & $\boldsymbol{m}_{\text {all }}$ & $\boldsymbol{m}_{\text {all }}$ & $\left.\boldsymbol{m}_{\text {all }}\right)$ \\
\hline \multirow[t]{2}{*}{$\ln (U)$} & 0.451 & 0.553 & 0.479 & 0.344 & 0.530 & 0.616 \\
\hline & $(0.008)$ & $(0.023)$ & $(0.025)$ & $(0.038)$ & $(0.025)$ & $(0.071)$ \\
\hline \multirow[t]{2}{*}{$\ln (V)$} & 0.467 & 0.387 & 0.427 & 0.571 & 0.463 & 0.353 \\
\hline & $(0.009)$ & $(0.022)$ & $(0.022)$ & $(0.041)$ & $(0.028)$ & $(0.079)$ \\
\hline \multirow[t]{2}{*}{$\ln \left(W^{*} y\right)$} & -0.082 & & 0.292 & & -0.401 & \\
\hline & $(0.016)$ & & $(0.039)$ & & $(0.054)$ & \\
\hline \multirow[t]{2}{*}{$\ln (W U)$} & & -0.200 & & 0.317 & & -0.408 \\
\hline & & $(0.026)$ & & $(0.049)$ & & $(0.104)$ \\
\hline \multirow[t]{2}{*}{$\ln (W V)$} & & 0.014 & & -0.046 & & -0.125 \\
\hline & & $(0.024)$ & & $(0.049)$ & & $(0.076)$ \\
\hline \multirow[t]{2}{*}{ Linear time trend } & -0.039 & -0.032 & -0.037 & -0.047 & -0.035 & -0.014 \\
\hline & $(0.001)$ & $(0.001)$ & $(0.004)$ & $(0.004)$ & $(0.004)$ & $(0.006)$ \\
\hline \multirow[t]{2}{*}{ Constant } & 6.805 & 6.736 & 2.641 & 4.050 & 8.977 & 7.773 \\
\hline & $(0.197)$ & $(0.132)$ & $(0.474)$ & $(0.335)$ & $(0.802)$ & $(0.854)$ \\
\hline $\mathrm{R}^{2}$ & 0.816 & 0.827 & 0.914 & 0.910 & 0.960 & 0.957 \\
\hline Observations & 2106 & 2106 & 180 & 180 & 180 & 180 \\
\hline
\end{tabular}

fer more about the structure of inter-regional dependencies in job creation, we estimate spatially augmented matching functions separately for clusters and hot spots and confront them with the results obtained from the pooled sample. The results are contained in Table 5.

The local pools of unemployment and vacancies have significantly positive coefficients in all specifications. The magnitudes of these coefficients are roughly comparable. The pooled sample exhibits a significantly negative, but comparably small elasticity of non-resident job creation activity. Instrumenting non-resident matches by non-resident unemployed job seekers and vacancies provides more detailed information. While for the pooled sample, spatially lagged unemployment has a significantly negative effect on new hirings, the effect of spatially lagged vacancies is insignificant. If one concentrates on clusters, the effect of spatially lagged unemployment becomes significantly positive: unemployed from neighboring regions search all regions that form a cluster for new employment, and accept jobs they get offered. Vacancies in neighboring regions again play no significant role. The opposite is true for hot spots: spatially lagged unemployment decreases job creation in a given hot spot region significantly, likewise do spatially lagged vacancy levels. This result could be expected given the negative spatial autocorrelation of hot spots, and the fact that the pools of unemployment and vacancies in spatially contiguous regions both affect job creation in these contiguous 
regions positively. Interestingly, the time trend is significantly negative and of roughly the same size for all specifications, indicating a fall in overall matching efficiency over time.

\subsection{The Effect of German Re-unification}

German re-unification has had a huge impact on German labor markets. When analyzing regional migration and job creation behavior, this event cannot be neglected. The question is whether re-unification has had any impact on inter-regional migration, e.g. because individuals started migrating to Western Germany for jobs trying to avoid unemployment or increase their salary. We approach this issue by regressing regional matching functions of the form of Equation (2) with an additional dummy for the post-reunification period. Since the data cover the years 1980 until 1997, the dummy takes the value zero for the years 1980 to 1989, and one for the later years. Table 6 contains results for different specifications of the dependent variable. The results of these regressions are striking. The effect of re-unification on all hirings turns out insignificant for both specifications, with spatial lags defined as affecting contiguous regions (neighbors) and non-contiguous regions (other regions which share no common border with the region in question). However, the dummy is highly significant and positive for matching functions with matches from non-neighboring regions, $m_{f}$, as dependent variable, and significantly negative for matches from neighboring regions, $m_{n}$, as regressand. ${ }^{9}$ This reflects the fact that migration from Eastern Germany indeed played an important role in the aftermath of re-unification. The negative effect on matches from contiguous regions originates from the fact that the source regions of flows from East German regions have by convention in the creation of the data set no common borders with West-German regions. ${ }^{10}$ Intensified flows from Eastern Germany therefore decreased the importance of 'neighboring migration'. Corroborating this is the finding that hirings of locals, $m_{h}$, have been negatively affected by re-unification. Further results not contained in the table suggest that if matches won by non-locals as a share of all matches or the ratio of non-local matches over local matches are taken to be the dependent variable, the re-unification dummy is highly significant

\footnotetext{
${ }^{9}$ Note that matches from non-contiguous regions are regressed on spatially lagged explanatory variables. For obvious reasons, spatial lags apply to non-contiguous regions in this case. On the other hand, for the specification with hirings from neighboring regions as dependent variable, explanatory variables are spatially lagged with lags pertaining to contiguous regions.

${ }^{10} \mathrm{As}$ a consequence, even if workers move from a contiguous Eastern region into a Western region, this would be recorded as a hiring from a non-contiguous region.
} 
and positive. This provides again strong evidence that overall regional mobility increased significantly as a consequence of the political process. These results confirm evidence provided by Hunt (2000) who also finds that there was substantial emigration from East to West Germany in the aftermath of re-unification. ${ }^{11}$

TABLE 6: EMPIRICAL MATChING FUNCTIONS WITH SPATIAL DEPENDENCE BY REgIONAL ORIGIN AND EFFECTS OF RE-UNIFICATION

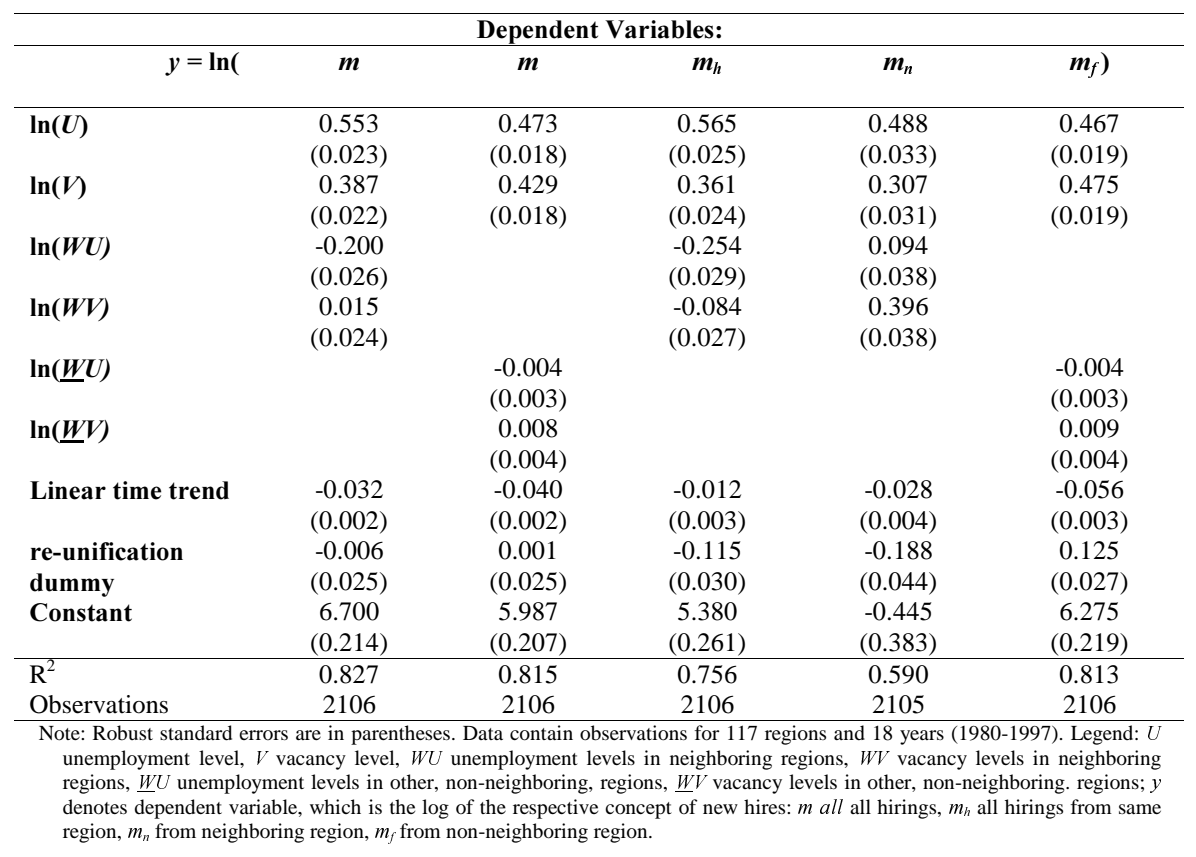

Interestingly, the coefficients of spatially lagged unemployment is not significantly different from zero if 'far-distance' migration $m_{f}$ is concerned, while the coefficient for spatially lagged vacancies is significantly negative, but relatively small. We take this as evidence for economy-wide cyclical effects.

\footnotetext{
${ }^{11}$ Hunt (2000) also finds that migration flows decreased substantially from high levels immediately after re-unfication to low levels during the mid-1990s. Our results allow for the same conclusions. The time trend is negative for the entire time period, but when estimating pre-unification and post-unification separately, the negative effect is strongest for the latter specification. Alternatively, the effect of an interacion term of time trend and reunification dummy is highly significant and negative.
} 


\section{Towards a Spatial Matching Framework}

While section 3 provided evidence for spatial autocorrelataion and spatial dependencies in the matching process, section 4 provided novel insights into on the spatial structure of new hires. However, so far the findings have not been tied together in order to set out an explicit spatial specification of the matching process. This will be done in the following. Before that, we present a simple theoretical framework in order to allow a more structured interpretation of the data.

\subsection{A Simple Model of Endogenous Search}

\section{Endogenous Mobility}

Assume an economy which consists of several regions. Some fraction of the population of a given region is unemployed at a given point in time, and looks for new employment. Job seekers only differ with respect to their current region of origin. Consider the regional migration decision of a given job seeker. For simplicity, we assume that job seekers always search within their home region. However, they have also the opportunity to search in other regions, and the decision to do so is endogenous and depends on the job prospects in other regions. An individual will decide to search elsewhere and migrate in case of finding new employment, if and only if the expected benefits outweigh the costs for searching abroad and migrating, that is if the expected net gains from searching elsewhere are positive. Hence, assume the intensity of search elswhere depends, ceteris paribus positively on the total number of new hires elsewhere, as intensive hiring activities suggest that it is relatively easy to find new employment. On the other hand, search intensity for jobs in other regions depends negatively on the unemployment rates in these regions: High local unemployment means fiercer competition for vacancies. Seen from the perspective of a region, the intensity of job search of non-residents, $\phi$, is therefore a positive function of the number of matches, $m$, in the region realized within a period, and a negative function of the regional unemployment level, $u_{h} \cdot{ }^{12}$

$$
\phi=\phi\left(m, u_{h}\right) \text { with } \frac{\partial \phi}{\partial m}>0, \text { and } \frac{\partial \phi}{\partial u_{h}}<0 .
$$

All new hires realized within a region during a period of time are composed of hires won by residents, $m_{h}$, and hires won by seekers from other

\footnotetext{
${ }^{12}$ These assumptions are in line with evidence from survey data, see Faini, Galli, Gennari, and Rossi (1997).
} 
regions, $m_{n}$ :

$$
m=m_{h}+m_{n} .
$$

Likewise, the total number of persons actively searching for employment in the region, $J$, consists of resident unemployed job seekers, $u_{h}$, and the fraction of non-residents who decide to look elswhere, $\phi u_{n}$ :

$$
J=u_{h}+\phi u_{n}
$$

Given this endogenous behavior, one can ask how this affects the composition of new successful matches. In particular, consider the share of new hires accessed by non-resident job seekers:

$$
\beta=\frac{m_{n}}{m}
$$

Assume, there is no discrimination, that is, every job seeker has the same probability of encountering a new job, $\theta$, regardless of his origin. Hence, the number of matches achieved by non-residents can be expressed as $m_{n}=\theta \phi u_{n}$. Substituting and using standard calculus, we obtain the first set of results:

$$
\begin{aligned}
\varepsilon_{\beta m} & =\frac{\partial \beta}{\partial m} \frac{m}{\beta}=\varepsilon_{\phi m}\left(1-\frac{\phi u_{n}}{u+\phi u_{n}}\right)>0 \\
\varepsilon_{\beta u_{h}} & =\varepsilon_{\phi u_{h}}\left(1-\frac{\phi u_{n}}{u+\phi u_{n}}\right)-\frac{u}{u+\phi u_{n}}<0 \\
\varepsilon_{\beta u_{n}} & =1-\frac{\phi u_{n}}{u+\phi u_{n}}>0 .
\end{aligned}
$$

Hence, the share of non-resident job accessions increases in the total number of matches, decreases in the level of resident unemployment, and increases in the level of non-resident unemployment.

We now turn to a different dimension of endogenous behavior: On-the-job search.

\section{Endogenous On-the-Job Search}

Neglect for a moment the regional dimension, and consider an economy in which individuals only differ by their employment status. In particular, assume that unemployed individuals always search for a new job inelastically. On the other hand, the number of employed searchers is endogenous and depends on the labor market conditions. For simplicity, and to make things

comparable, let the search intensity of employed, $\psi$, depend positively on the 
number of total new hirings, and negatively on the number of unemployed job seekers, as they compete for the same jobs:

$$
\psi=\psi(m, u) \text { with } \frac{\partial \psi}{\partial m}>0 \text { and } \frac{\partial \psi}{\partial u}<0 .
$$

For simplicity, assume that there is no ranking of job applicants unlike in Blanchard and Diamond (1994). Analogous to the mobility model, all new hires are composed of hires of previously unemployed $m_{u}$, and job switchers $m_{e}: m=m_{u}+m_{e}$, and the total number of job seekers is the sum of unemployed $(u)$ and employed $(\psi e)$ searchers. As before, we are interested in the composition of new matches, which is now measured as the share of new hires of unemployed job seekers:

$$
\gamma=\frac{m_{u}}{m}
$$

This allows to derive the second set of results: ${ }^{13}$

$$
\begin{aligned}
\varepsilon_{\gamma m} & =-\varepsilon_{\psi m} \frac{\psi e}{\psi e+u}<0, \\
\varepsilon_{\gamma u} & ==\frac{\psi e}{\psi e+u}\left(1-\varepsilon_{\psi u}\right)>0 .
\end{aligned}
$$

We therefore expect the share of new hires accessed by unemployed to be negatively related to the overall level of hiring as a consequence of job competition and crowding out, and positively related to the number of unemployed job seekers. ${ }^{14}$

Before testing the empirical relevance of these and the previous results, we can combine them in order to get predictions for a world in which individuals searching for a new job are heterogeneous with respect to two dimensions: geographic origin and employment status.

\section{Putting Things Together}

Ex ante, it is not clear how endogenous regional mobility should be related with endogenous on-the-job search behavior. Nevertheless, the results obtained so far allow to predict how endogenous inter-regional mobility and job competition between unemployed and employed searchers affect job creation patterns. Consider, for example, the fraction of new hires made up by

\footnotetext{
${ }^{13}$ This setting follows closely the framework suggested by Anderson and Burgess (2000).

${ }^{14}$ It can be shown that $\varepsilon_{\gamma u}=0$ if there is ranking of applicants by employers and if employed job seekers are preferred by firms, see also Anderson and Burgess (2000).
} 
employed individuals immigrating from another region:

$$
\eta=\frac{m_{e n}}{m}
$$

Given the previous results, expects this ratio to increase in the number of matches, to decrease in the number of unemployed in the destination region, and to increase in the number of unemployed elsewhere:

$$
\begin{aligned}
\varepsilon_{\eta m} & >0 \text { as } \varepsilon_{\beta m}>0 \text { and } \varepsilon_{\gamma m}<0 \\
\varepsilon_{\eta u_{h}} & <0 \text { as } \varepsilon_{\beta u_{h}}<0 \text { and } \varepsilon_{\gamma u}>0 \\
\varepsilon_{\eta u_{n}} & >0 \text { as } \varepsilon_{\beta u_{n}}>0 \text { and } \varepsilon_{\gamma u}>0
\end{aligned}
$$

To show these results, note that the behavior of the share of matches of employed job seekers behaves inversely to the share of unemployed job seekers. Similarly, a blend of the previous models can help predicting the behavior of the fraction of new hires of resident unemployed:

$$
\zeta=\frac{m_{u h}}{m} .
$$

The models then imply:

$$
\begin{aligned}
& \varepsilon_{\zeta m}<0 \text { as } \varepsilon_{\beta m}>0 \text { and } \varepsilon_{\gamma m}<0 \\
& \varepsilon_{\zeta u_{h}}>0 \text { as } \varepsilon_{\beta u_{h}}<0 \text { and } \varepsilon_{\gamma u}>0 \\
& \varepsilon_{\zeta u_{n}}>0 \text { as } \varepsilon_{\beta u_{n}}>0 \text { and } \varepsilon_{\gamma u}>0
\end{aligned}
$$

However, it is less clear from the theoretical model, how fractions of new hires made up by unemployed non-residents and new hires of resident employed job seekers behave. The effects essentially depend on the relative intensities in the endogenous behavior.

It is worth noting that the results presented so far do not immediately follow from the assumptions about endogenous mobility and search behavior. While these affect the absolute magnitudes of respective flows, the behavior of the relative flows is mainly determined by the fact that the search intensity of some groups (in the cases above of resident and unemployed job seekers, respectively) is less elastic with respect to market conditions than that of the groups assumed to adjust their search behavior explicitly to market conditions (non-residents and employed job seekers).

\subsection{Empirical Application}

A problem for testing the endogenous mobility and job competition model with data is the fact that endogenous on-the-job search, as well as active 
search in other regions than the one individuals live in, is unobservable. Therefore, tests for the relevance of the model have to be somehow indirect. The approach taken here is to test the implications of the model with respect to the determinants of flows and the composition of flows. In order to do that, we estimate the following basic specification:

$$
\ln r a t_{i t}=\alpha_{0}+\alpha_{1} \ln U_{i t}+\alpha_{2} \ln V_{i t}+\alpha_{3} \ln W U_{i t}+T+U N I+\varepsilon_{i t},
$$

where $U_{i t}$ is the stock of unemployed in region $i$ at time $t, V_{i t}$ is the stock of vacancies, and $W U_{i t}$ is the spatially lagged level of unemployment of region $i$ at time $t .^{15} T$ is a linear time trend, $U N I$ represents a dummy taking the value 1 for years after German reunification, that is from 1990 onwards, and $\varepsilon$ is an i.i.d. error term. As dependent variable, we consider different specifications of $r_{i t}$, which represents the fraction of hires of workers exhibiting a particular characteristic with respect to all hires between period $t$ and $t+1$. These characteristics are regional origin of newly hired workers (from same region or from another region) and employment status during search (employed or unemployed), as well as combinations of these.

Table 7 contains estimation results for different specifications of the dependent variable. Column (1) allows to test the predictions of the endogenous mobility model, stated in equations (7) to (9), by using the fraction of hires constituted by individuals stemming from the respective neighboring regions. The predictions are strongly confirmed in the data. As a robustness check, the same model is estimated for the fraction of matches made up by individuals from anywhere else but the region where they are hired. Again, the model predictions are validated, as is seen in Column (2). A further robustness check, which also examines the validity of the assumption of orthogonality of the two sorts of endogenous search behavior, is conducted in Column (3): the dependent variable is matches of previously unemployed persons stemming originally from a neighboring region, as a fraction of all matches of unemployed job seekers in a region. Again, the results are precisely as predicted by the endogenous mobility model.

Column (4) contains estimation results for the fraction of all new hires constituted by unemployed applicants. This specification tests the implications of the job competition model between employed and unemployed seekers, as stated in equations (12) and (13). The predictions of the theoretical model are largely validated. The only exception is the slightly unexpected

\footnotetext{
${ }^{15}$ The spatially lagged stock of unemployed of a region $i$ is the (weighted) average of unemployment levels in neighboring regions. An alternative specification we used was the (weighted) average of unemployment levels in other regions, which have no common border with the respective region of interest. However, the results were unaffected by this.
} 
TAble 7: Patterns of Regional Mobility AND Job CoMPetition

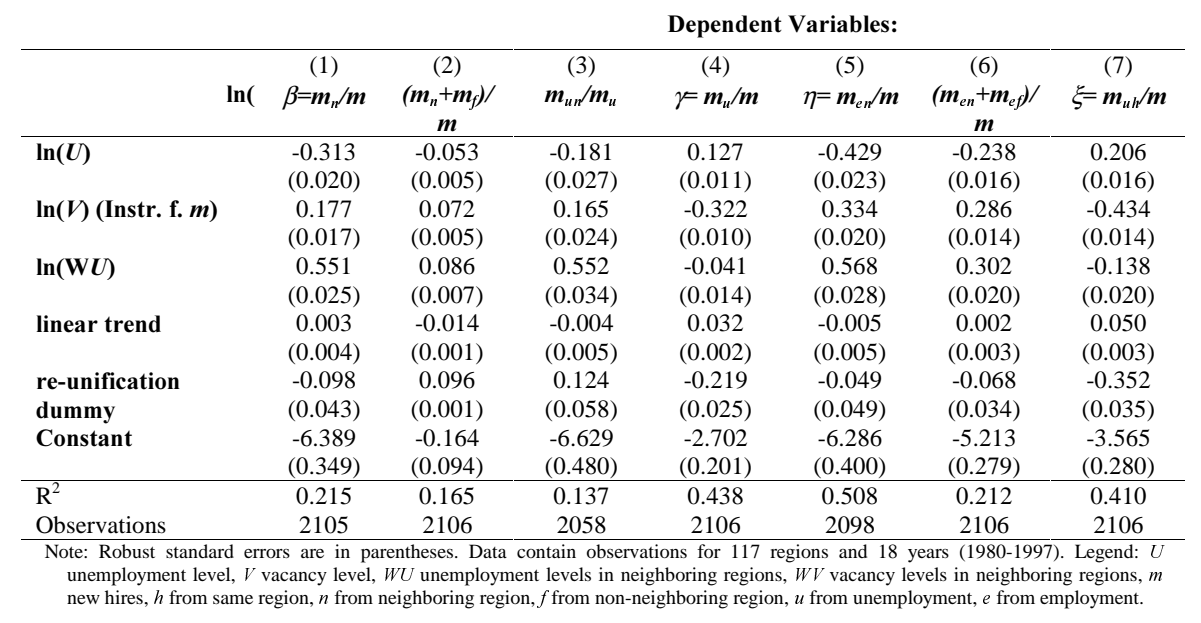

negative effect of the unemployment rate in neighboring regions. The negative sign of spatially lagged unemployment indicates that the job competition model alone cannot explain the data. The reason is that because there is no spatial dimension, the model would lead to similar predictions for the effect of local unemployment and unemployment in neighboring regions. We take this as further piece of evidence that the spatial dimension plays an important role in explaining the data. ${ }^{16}$

In Columns (5), (6) and (7), we test the predictions of the model combining endogenous mobility and endogenous on-the-job search. The predictions for the fraction of matches of employed non-resident applicants, as described in equations (15) to (17), are tested for newly hired from neighboring regions in Column (5). The effects are highly significant and exhibit the expected signs, corroborating the simple framework. The same is true if the fraction of all successful non-resident employed applicants is chosen as dependent variable, as is seen in Column (6). Finally, Column (7) regresses successful unemployed resident job seekers as a fraction of all new hires, in order to evaluate the predictions stated in equations (19) to (21). The predictions are again confirmed by the data.

To conclude, the results indeed provide evidence in favor of this behavioral hypotheses of the model: local regional unemployment has a significantly negative effect on regional 'employment immigration', while local vacancy rates increase the share of immigrants finding a new job in a region. This finding

\footnotetext{
${ }^{16}$ Robustness checks analogous to columns (2) and (3) for the mobility model, confirmed these results. A more extensive set of estimation results is available from the authors upon request.
} 
is also robust with respect to alternative specifications of the share of hires of non-local applicants, such as the ratio of matches formerly unemployed or employed individuals over all matches, or the ratio of non-local matches over local matches. ${ }^{17}$

\section{Conclusion}

This paper investigates spatial dependencies across regional labor markets, in particular with regard to job creation. We find strong evidence for spatial autocorrelation in hirings for some labor market regions in West Germany. In particular, we isolate regions with significantly positive spatial autocorrelation in job creation (clusters), and regions where hirings are characterized by significantly negative spatial autocorrelation (hot spots). Furthermore, the results indicate that conventional empirical matching functions neglecting the spatial component are misspecified. We provide evidence that spatial lag models characterize the matching process better.

The estimation results for spatially augmented matching functions indicate that job creation is negatively affected by job creation in contiguous regions. Spatially lagged unemployment affects the hiring process in a given region negatively. This result is robust for several concepts of flows to employment. Once spatial matching functions are estimated separately for clusters and hot spots, these findings are put into perspective, with spatially lagged unemployment affecting hires positively in clusters, but negatively in hot spots. In general, the findings indicate that the concept of a matching function is empirically confirmed even in the presence of an explicit spatial dimension. German re-unification increased new hires from non-neighboring regions, which include among others also East German regions, significantly.

In order to ascertain how the spatial composition of new matches is determined, a more structural approach is developed. We present a simple model of inter-regional job search and endogenous on-the-job search. The empirical evidence validates the basic implications of the model. Unlike previous studies for other countries, we find evidence for endogenous mobility decisions determined by labor market conditions. Moreover, there is evidence for endogenous on-the-job search. The data confirm also the predictions of a combined model of endogenous search along two dimensions: regions and employment status.

\footnotetext{
${ }^{17}$ More detailed results are available from the authors upon request.
} 


\section{References}

Anderson, P. M., And S. M. Burgess (2000): "Empirical Matching Functions: Estimation and Interpretation Using State-Level Data," Review of Economics and Statistics, 82(1), 90-102.

Anselin, L., And A. K. Bera (1999): Spatial Dependence in Linear Regression Models with an Introduction to Spatial Econometrics, vol. 155. Dekker.

Antolin, P., And O. Bover (1997): "Regional Migration in Spain: The Effect of Personal Characteristics and of Unemployment, Wages and House Price Differentials Using Pooled Cross Sections," Oxford Bulletin of Economics and Statistics, 59(2), 215-235.

Bender, S., A. HaAs, and C. Klose (2000): "IAB Employment Subsample 1975-1995. Opportunities for Analysis Provided by the Anonymised Subsample," .

Blanchard, O. J., and P. Diamond (1994): "Ranking, Unemployment Duration, and Wages," Review of Economic Studies, 61(3), 417-437.

Burda, M. C., and S. Profit (1996): "Matching Across Space: Evidence on Mobility in the Czech Republic," Labour Economics, 3(3), 255-278.

Burgess, S., And S. Profit (2001): "Externalities in the Matching of Workers and Firms in Britain," Labour Economics, 8(3), 313-333.

DaVanzo, J. (1978): "Does Unemployment Affect Migration? Evidence From Micro Data," Review of Economics and Statistics, 60(4), 504-514.

Faini, R., G. Galli, P. Gennari, and F. Rossi (1997): "An Empirical Puzzle: Falling Migration and Growing Unemployment Differentials Among Italian Regions," European Economic Review, 41(4), 571-579.

Gorter, C., And J. VAn Ours (1994): "Matching Unemployment and Vacancies in Regional Labor Markets: An Empirical Analysis for the Netherlands," Papers in Regional Science, 73(2), 153-167.

Greenwood, M. J. (1997): "Internal Migration in Developed Countries," in Handbook of Population and Family Economics, ed. by M. Rosenzweig, and O. Stark, chap. 12, pp. 647-720. Elsevier, Amsterdam.

Hunt, J. (2000): "Why Do People Still Live in East Germany?," NBER Working Paper, 7564. 
Kugler, A. D., and G. Saint-Paul (2001): "How do Firing Costs affect Worker Flows in a World with Adverse Selection?," mimeo.

Petrongolo, B., and C. Pissarides (2001): "Looking Into the Black Box: A Survey of the Matching Function," Journal of Economic Literature, 39(2), 390-431.

Pissarides, C. A., and J. Wadsworth (1989): "Unemployment and the Inter-Regional Mobility of Labour," Economic Journal, 99(397), 739-755.

Sunde, U. (2002): "Unobserved Bilateral Search on the Labor Market: A Theory-Based Correction for a Common Flaw in Empirical Matching Studies," IZA Discussion Paper, 520. 


\section{A Alternative measures of spatial autocorre- lation}

An alternative measure of spatial autocorrelation is Geary's c:

$$
c=(N-1) \frac{\sum_{i=1}^{N} \sum_{j=1}^{N} w_{i j}\left(\left(Y_{i}-\bar{Y}\right)\left(Y_{j}-\bar{Y}\right)\right)^{2}}{2 N\left(\sum_{i=1}^{N} \sum_{j=1}^{N} w_{i j}\right) \sum_{i=1}^{N} \frac{\left(Y_{i}-\bar{Y}\right)^{2}}{N}} .
$$

The expected value of $c$ equals 1 under the null of no spatial autocorrelation. If $c$ is larger than this, the distribution of $Y$ exhibits negative spatial autocorrelation, if $c$ is smaller than $1, Y$ is negatively spatially autocorrelated. Similar to Moran's $I$, inference is based on $z(c)=\frac{c-1}{s d(c)}$.

Additionally to spatial autocorrelation, Getis and Ord's $G$ also responds to the prevalence of clusters of regions:

$$
G=\frac{\sum_{i \neq j} w_{i j} Y_{i} Y_{j}}{\sum_{i \neq j} Y_{i} Y_{j}}
$$

Under the null of no spatial autocorrelation, the expected value of $G$ equals $E(G)=\frac{\sum_{i} \sum_{j} w_{i j}}{N(N-1)}$. If $G$ is larger than this value, this is evidence that $Y$ 's distribution exhibits positive spatial autocorrelation and high-valued clusters. If the value of $G$ is smaller, the distribution of $Y$ is characterized by positive spatial autocorrelation and low-valued clusters. As in the other cases, inference is based on $z(G)=\frac{G-E(G)}{s d(G)}$.

\section{B West German Labor Market Regions}

As discussed briefly in the data section, the definition of labor market regions used in the data follows the definitions of the German Federal Institute of Employment Research, and the German Federal Office for Building and Regional Planning. Whenever the two concepts did not coincide, the data were aggregated up to the coarser definition. Table A1 contains a list of the regions used in the analysis, followed by a map illustrating the geographic location of the regions. 
TABLE A1: Regional LABOR MARKETS FOR WEST GERMANY

\begin{tabular}{|c|c|c|c|}
\hline $\begin{array}{r}\text { Region } \\
\text { number }\end{array}$ & Region & $\begin{array}{r}\text { Region } \\
\text { number }\end{array}$ & Region \\
\hline 1 & Flensburg & 64 & Landau \\
\hline & Hamburg, incl. Bad Oldesloe, & 65 & Ludwigshafen \\
\hline 2 & Elmshorn, Stade & 66 & Mainz \\
\hline 3 & Heide & 67 & Montabaur \\
\hline 4 & Kiel incl. Neumünster & 68 & Neuwied \\
\hline 5 & Lübeck & 69 & Pirmasens \\
\hline 6 & Braunschweig & & Saarbrücken, incl. Neunkirchen, \\
\hline 7 & Bremen, incl. Bremerhaven, Verden & 70 & Saarlouis \\
\hline 8 & Celle & 71 & Trier \\
\hline 9 & Emden & 72 & Aalen \\
\hline 10 & Goslar & 73 & Balingen \\
\hline 11 & Göttingen & 74 & Freiburg \\
\hline 12 & Hameln & 75 & Heidelberg \\
\hline 13 & Hannover & 76 & Heilbronn \\
\hline 14 & Helmstedt & 77 & Karlsruhe \\
\hline 15 & Hildesheim & 78 & Konstanz \\
\hline 16 & Leer & 79 & Lörrach \\
\hline 17 & Lüneburg & 80 & Mannheim \\
\hline 18 & Nienburg & 81 & Nagold \\
\hline 19 & Nordhorn & 82 & Offenburg \\
\hline 20 & Oldenburg & 83 & Pforzheim \\
\hline 21 & Osnabrück & 84 & Rastatt \\
\hline 22 & Uelzen & 85 & Ravensburg \\
\hline 23 & Vechta & 86 & Reutlingen \\
\hline 24 & Wilhelmshaven & 87 & Rottweil \\
\hline 25 & Aachen & 88 & Schwäbisch Hall \\
\hline 26 & Bergisch Gladbach & & Stuttgart, incl. Göppingen, \\
\hline 27 & Bielefeld, incl. Herford & 89 & Ludwigsburg, Waiblingen \\
\hline 28 & Bochum & 90 & Tauberbischofsheim \\
\hline 29 & Bonn & 91 & Ulm \\
\hline 30 & Detmold & 92 & Villingen-Schwenningen \\
\hline 31 & Dortmund, incl. Hamm & 93 & Ansbach \\
\hline 32 & Düren & 94 & Aschaffenburg \\
\hline 33 & Düsseldorf & 95 & Bamberg \\
\hline 34 & Duisburg., incl. Oberhausen, Wesel & 96 & Bayreuth \\
\hline 35 & Essen & 97 & Coburg \\
\hline 36 & Gelsenkirchen, incl. Recklinghausen & 98 & Hof \\
\hline 37 & Hagen & 99 & Nürnberg, incl. Weissenburg \\
\hline 38 & Iserlohn & 100 & Regensburg \\
\hline 39 & Köln, incl. Brühl & 101 & Schwandorf \\
\hline 40 & Krefeld & 102 & Schweinfurt \\
\hline 41 & Meschede & 103 & Weiden \\
\hline 42 & Mönchengladbach & 104 & Würzburg \\
\hline 43 & Münster, incl. Ahlen, Coesfeld & 105 & Augsburg \\
\hline 44 & Paderborn & 106 & Deggendorf \\
\hline 45 & Rheine & 107 & Donauwörth \\
\hline 46 & Siegen & 108 & Ingolstadt \\
\hline 47 & Soest & 109 & Kempten \\
\hline 48 & Wuppertal, incl. Solingen & 110 & Landshut \\
\hline 49 & Bad Hersfeld & 111 & Memmingen \\
\hline 50 & Darmstadt & 112 & München, incl. Freising \\
\hline 51 & Frankfurt, incl. Offenbach & 113 & Passau \\
\hline 52 & Fulda & 114 & Pfarrkirchen \\
\hline 53 & Gießen & 115 & Rosenheim \\
\hline 54 & Hanau & 116 & Traunstein \\
\hline 55 & Kassel & 117 & Weilheim \\
\hline 56 & Korbach & & \\
\hline 57 & Limburg & & \\
\hline 58 & Marburg & & \\
\hline 59 & Wetzlar & & \\
\hline 60 & Wiesbaden & & \\
\hline 61 & Bad Kreuznach & & \\
\hline 62 & Kaiserslauten & & \\
\hline 63 & Koblenz, incl. Mayen & & \\
\hline
\end{tabular}




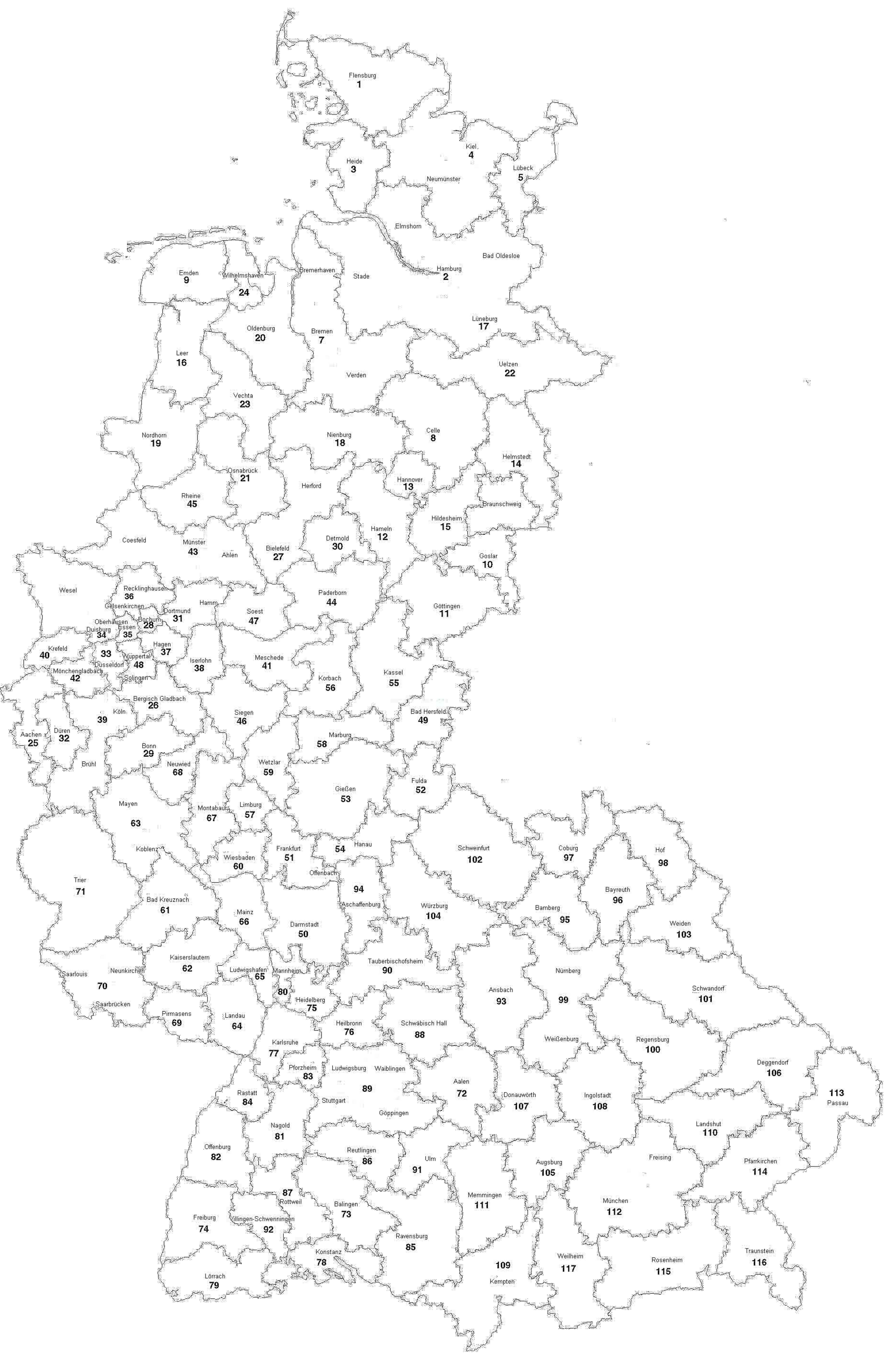




\section{IZA Discussion Papers}

\begin{tabular}{|c|c|c|c|c|}
\hline No. & Author(s) & Title & Area & Date \\
\hline 504 & $\begin{array}{l}\text { L. Cappellari } \\
\text { S. P. Jenkins }\end{array}$ & Modelling Low Income Transitions & 4 & $05 / 02$ \\
\hline 505 & T. K. Bauer & Migration, Sozialstaat und Zuwanderungspolitik & 1 & 05/02 \\
\hline 506 & $\begin{array}{l}\text { P. Díaz-Vázquez } \\
\text { D. Snower }\end{array}$ & Can Insider Power Affect Employment? & 3 & $05 / 02$ \\
\hline 507 & $\begin{array}{l}\text { E. Fehr } \\
\text { A. Falk }\end{array}$ & Psychological Foundations of Incentives & 5 & $05 / 02$ \\
\hline 508 & $\begin{array}{l}\text { C. Belzil } \\
\text { J. Hansen }\end{array}$ & Unobserved Ability and the Return to Schooling & 6 & $05 / 02$ \\
\hline 509 & A. Kunze & $\begin{array}{l}\text { The Timing of Careers and Human Capital } \\
\text { Depreciation }\end{array}$ & 1 & $06 / 02$ \\
\hline 510 & E. S. Prasad & Wage Inequality in the United Kingdom, 1975-99 & 2 & $06 / 02$ \\
\hline 511 & $\begin{array}{l}\text { F. Büchel } \\
\text { H. Battu }\end{array}$ & $\begin{array}{l}\text { The Theory of Differential Overqualification: } \\
\text { Does it Work? }\end{array}$ & 1 & $06 / 02$ \\
\hline 512 & $\begin{array}{l}\text { C. Belzil } \\
\text { J. Hansen }\end{array}$ & $\begin{array}{l}\text { A Structural Analysis of the Correlated Random } \\
\text { Coefficient Wage Regression Model }\end{array}$ & 6 & $06 / 02$ \\
\hline 513 & $\begin{array}{l}\text { C. Belzil } \\
\text { J. Hansen }\end{array}$ & $\begin{array}{l}\text { Earnings Dispersion, Risk Aversion and } \\
\text { Education }\end{array}$ & 6 & $06 / 02$ \\
\hline 514 & F. Schneider & $\begin{array}{l}\text { The Size and Development of the Shadow } \\
\text { Economies of } 22 \text { Transition and } 21 \text { OECD } \\
\text { Countries }\end{array}$ & 4 & $06 / 02$ \\
\hline 515 & $\begin{array}{l}\text { J. Hurley } \\
\text { R. Vaithianathan } \\
\text { T. F. Crossley } \\
\text { D. Cobb-Clark }\end{array}$ & $\begin{array}{l}\text { Parallel Private Health Insurance in Australia: } \\
\text { A Cautionary Tale and Lessons for Canada }\end{array}$ & 3 & $06 / 02$ \\
\hline 516 & H. Bonin & $\begin{array}{l}\text { Eine fiskalische Gesamtbilanz der Zuwanderung } \\
\text { nach Deutschland }\end{array}$ & 7 & $06 / 02$ \\
\hline 517 & E. Tekin & $\begin{array}{l}\text { Child Care Subsidies, Wages, and Employment } \\
\text { of Single Mothers }\end{array}$ & 3 & $06 / 02$ \\
\hline 518 & $\begin{array}{l}\text { P. Carneiro } \\
\text { J. J. Heckman }\end{array}$ & $\begin{array}{l}\text { The Evidence on Credit Constraints in } \\
\text { Post-Secondary Schooling }\end{array}$ & 5 & $06 / 02$ \\
\hline 519 & $\begin{array}{l}\text { S. Cohen } \\
\text { Z. Eckstein }\end{array}$ & $\begin{array}{l}\text { Labor Mobility of Immigrants: Training, } \\
\text { Experience, Language and Opportunities }\end{array}$ & 1 & $06 / 02$ \\
\hline 520 & U. Sunde & $\begin{array}{l}\text { Unobserved Bilateral Search on the Labor } \\
\text { Market: A Theory-Based Correction for a } \\
\text { Common Flaw in Empirical Matching Studies }\end{array}$ & 1 & $06 / 02$ \\
\hline 521 & $\begin{array}{l}\text { U. Sunde } \\
\text { R. Fahr }\end{array}$ & $\begin{array}{l}\text { Employment Status, Endogenous Regional } \\
\text { Mobility, and Spatial Dependencies in Labor } \\
\text { Markets }\end{array}$ & 1 & $06 / 02$ \\
\hline
\end{tabular}

